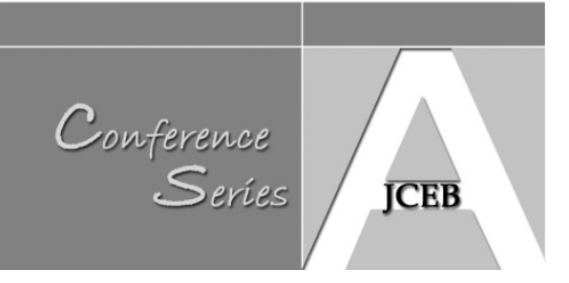

\title{
Engineering Sketching: A Valuable Teaching Tool in Construction
}

Samad Sepasgozar and Leonhard Bernold (University of New South Wales, Australia)

\begin{abstract}
Sketching in general engineering and science has been "outmanoeuvred" by computer graphics while still holding on in architectural engineering as a tool to think about spatial relationships, allowing the students to develop conceptual designs quicker than any CAD. Moreover, a recent paper reported that sketching helped students in geology develop critical thinking skills. Based on students' feedback, it was concluded that it led to a deeper understanding of important concepts. Should it surprise us that psychological research shows that sketching facilitates inference, discovery and learning? This paper presents a model for creating and assessing assignments that uses engineering sketching to teach and learn in a second year course at UNSW, CVEN2101-Engineering Construction. The class focuses on studying key principles related to the safe and effective utilization of construction equipment such as trucks, excavators, cranes and temporary structures. Students faced the challenge to investigate how the physics and math relate to digging, lifting and the creation of large forces while keeping labourers safe. The concept of forensic engineering had to be used to study the cause of accidents. The developed model includes various measurements and proper motion paths, in an attempt to quantify the level of understanding. It is felt, that based on the findings of this study, that engineering sketching not only allows inventing new mechanisms, as Leonardo da Vinci did, but equally important, provides a valuable and reliable tool to teach and learn construction engineering.
\end{abstract}

Keywords: Engineering Sketch, Construction, Teaching Tool, Assessment, Model.

\section{Introduction}

Leonardo da Vinci left humankind a legacy that can be easily understood by every engineer because he was the true master of using sketching as a means to think and communicate (White 2000). Garner (1990) asserts that its role is similar to the creation, development, evaluation, communication and sharing of ideas, although Prats et al. (2009) claim the style of sketches may differ in various fields. There is a considerable amount of research which focuses on communication as a common medium for a sketch such as Barr (2004) and Henderson (1991). In the field of engineering it has been studied as a means for sharing, designing and complementing the capability of computers (Verstijnen et al. 1998; Company et al. 2005). Still, Varley and Company (2008) reported that graphical literacy has been declining in engineering and science. All the while, no research has focused on studying the contribution of engineering sketches to improve the students' understanding of a subject, especially in construction engineering. In this particular course, second year students are exposed to a supposedly simply process, excavation, requiring math and many areas of physics to model and plan an operation that includes trucks cycling back and forth. Also, it is difficult to verbally express how technically failure caused an accident during the construction.

As mentioned earlier, engineering sketching might be an excellent tool not only to explain complex processes but also to enhance the learning of students. Johnson and Reynolds (2005) tested the effect of sketches in learning in Geology. They reported that 
sketching helped students to think more deeply and reflect on what they learned. Based on students' feedback, it was concluded that it leads to a deeper understanding of important concepts. Tversky (2002), in another study, found that sketching was useful for scrutinizing one's own ideas. He believes that a sketch includes key information, and furthermore, is able to represent the structure of information or the lack thereof. It is easy to envisage that sketching might be able to boost students' understanding of certain course material and guide them to achieve higher course objectives.

This paper presents how sketches assist students to more deeply understand construction systems and equipment in static and dynamic conditions. It also explains how it was used to teach and assess student understanding of construction operations designed for safety, quality and productivity. An outcome-based teaching model focused on four main themes for which measures for assessment were generated. The goal was to establish assessment criteria that quickly revealed the level of understand by the way the student portrays key elements in the engineering sketch.

\section{Method of Study}

The goal of the work discussed in this paper was to test the effect of engineering sketching as a means to improve teaching and learning. A model was developed, implemented and reviewed in a second year course that covered a variety of basic construction related topics such as cost, power, safety and technologies. 181 students in a second year course at UNSW, CVEN2101 Engineering Construction, were given three sketching assignments at a special workshop and learned how to peer review each others' work based on a set of criteria. In fact, peer review was an important element of the teaching approach/ pedagogy in embracing active learning and formative assessment. All students participated in selecting four best sketches for each of three themes. These twelve chosen sketches were shown in the class and finally, the winners' sketches appeared on the in house TV network.

\section{The "ESTL" Model}

The underlying structure was put together in a model referred to as Engineering Sketching for Teaching and Learning (ESTL). It is primarily supported by two different types of resources, a text book and in class Powerpoint made available on the class website. Figure 1 presents the structure of the model beginning with the course profile. Four main focus areas were selected from a pool of 10 possibilities: (A) Systems for Construction, (B) Forces - Power, (C) Work Place and Safety, (D) Operational Planning. Subsequently, learning outcomes for each were defined such as "ability to break down complexity" and "safety rules" shown in Figure 1. For example, while knowing the pertinent safety rules is important in focus area C, it was important to teach the students to actually include its principles in the Operational Planning, focus area D. At the same time, the ability to plan an operation needs to include an understanding of the functions of various components of all the systems.

Figure 1 also indicates that learning outcomes are defined according to the objectives of each focus area. For example, focus A expects that students will be able to break a large production system into sub-systems and then model, calculate and balance resources in order to achieve the highest production rates for distributed task durations. The following section introduces an approach to assess how well a student masters the desired learning outcomes.

Sepasgozar, S. and Bernold, L. (2012) 'Engineering sketching: a valuable tool in construction', Australasian Journal of Construction Economics and Building, Conference Series, 12 (1) 62-72 


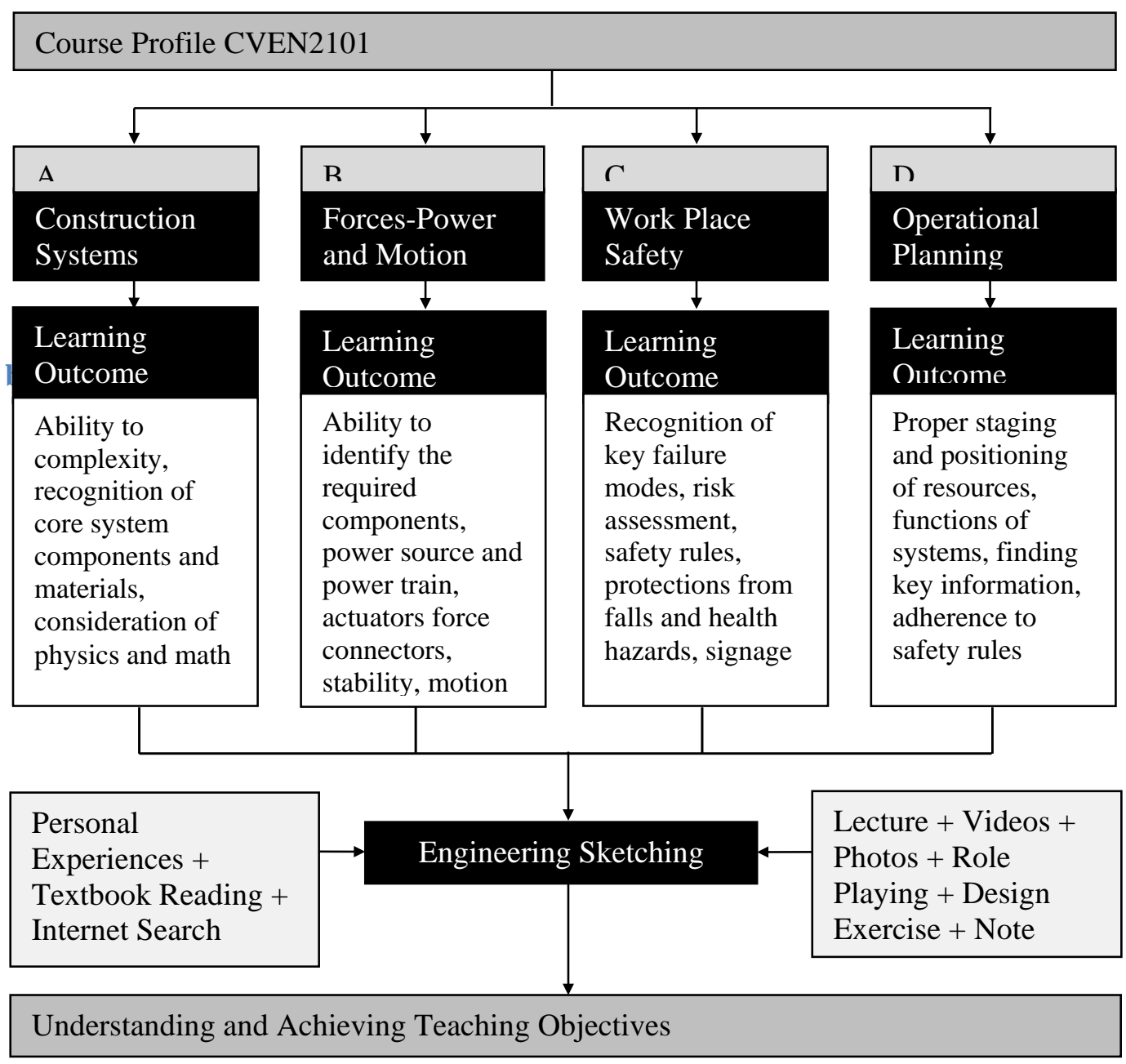

Figure 1 ESTL Model for Construction Engineering

\section{Design of the ESTL Assessment Matrix}

It is apparent that each focus area consists of multiple outcomes that will require a list of assessment criteria each. This situation led to the creation of a matrix that is structured according to the four focus areas A-C. Table 1 displays how each is broken down into outcome attributes and related measures that indicate professionalism and level of understanding. For example, hoist cables of cranes that are not sketched vertically show that the student has not grasped that cranes are strictly designed for vertical lifting only. It also indicates a lack of reflective thinking as the textbook and the class presentations, using "catastrophic" videos of toppling cranes, emphasized on numerous occasions this critical requirement. As expected, the outcome attributes are, with the exception of process modelling, related to physical aspects of mobile and fixed systems such as stability, power and safety. 
Table 1 Outcome Based ESTL Matrix

\begin{tabular}{|c|c|c|}
\hline COMPETENCY & $\begin{array}{l}\text { OUTCOME } \\
\text { ATTRIBUTES }\end{array}$ & MEASURES OF UNDERSTANDING \\
\hline \multirow{6}{*}{$\begin{array}{l}\text { Systems in } \\
\text { Construction }\end{array}$} & $\begin{array}{l}\text { Production process } \\
\text { model }\end{array}$ & $\begin{array}{l}\text { Does model consider all the necessary resources, } \\
\text { flows, logical task sequence, durations and cycles? }\end{array}$ \\
\hline & $\begin{array}{l}\text { Form-size-scale- } \\
\text { relationships- } \\
\text { connections of essential } \\
\text { elements of mechanical } \\
\text { systems }\end{array}$ & $\begin{array}{l}\text { Proper sizing and joints between elements/parts are } \\
\text { essential to prevent system failure. Do forms of main } \\
\text { components conform to reality? (i.e., wheels are } \\
\text { round). Are the elements sized, scaled and connected } \\
\text { properly? (i.e., truck tire-chassis) }\end{array}$ \\
\hline & Motion path-limitations & $\begin{array}{l}\text { Mechanical production systems move based on rules of } \\
\text { trigonometry. Are motion paths depicted accurately? }\end{array}$ \\
\hline & $\begin{array}{l}\text { Levelness-plumbness- } \\
\text { stability }\end{array}$ & $\begin{array}{l}\text { Mobile and fixed structures need firm foundations, } \\
\text { supports and stable components. Is the mechanical } \\
\text { system and its elements level, plumb and stable? }\end{array}$ \\
\hline & $\begin{array}{l}\text { Material-component } \\
\text { shapes }\end{array}$ & $\begin{array}{l}\text { A mechanical system commonly consists of various } \\
\text { materials. Are the differing component materials and } \\
\text { shapes recognized? (e.g. rubber tire vs. steel rim). }\end{array}$ \\
\hline & Environment & Does the work environment fit the system? \\
\hline \multirow{3}{*}{$\begin{array}{l}\text { Forces-Power } \\
\text { and Motion }\end{array}$} & $\begin{array}{l}\text { Power source-power } \\
\text { train }\end{array}$ & $\begin{array}{l}\text { A mechanical production system needs power and a } \\
\text { means to apply it properly. Is the source of power and } \\
\text { its distribution shown? (e.g., hydraulic pump and } \\
\text { hoses). }\end{array}$ \\
\hline & Main actuators & $\begin{array}{l}\text { Without actuators a system stays fixed and immobile } \\
\text { (e.g., hydraulic cylinders and motors). Are the } \\
\text { actuators able to apply the necessary forces to create } \\
\text { motion? }\end{array}$ \\
\hline & Stability & $\begin{array}{l}\text { External forces will act on mechanical systems. Are } \\
\text { the acting and reacting forces in balance? }\end{array}$ \\
\hline \multirow{4}{*}{$\begin{array}{l}\text { Work Place } \\
\text { Safety }\end{array}$} & Fall protection & $\begin{array}{l}\text { Falls from a height is one of the primary causes of } \\
\text { death in construction. Are labourers protected against } \\
\text { falls? }\end{array}$ \\
\hline & Required signage & $\begin{array}{l}\text { Are the signs and barricades warning/protecting against } \\
\text { unsafe behaviour in place? }\end{array}$ \\
\hline & Barricades & $\begin{array}{l}\text { Is there sufficient distance around moving systems } \\
\text { barricaded off? }\end{array}$ \\
\hline & Health hazards & $\begin{array}{l}\text { Are the operators and drivers protected against Noise, } \\
\text { Fumes, Heat, Nails and Drop? Are the workers } \\
\text { wearing the enquired safety gear? }\end{array}$ \\
\hline \multirow{3}{*}{$\begin{array}{l}\text { Operational } \\
\text { Planning }\end{array}$} & $\begin{array}{l}\text { Staging-positioning of } \\
\text { resources }\end{array}$ & $\begin{array}{l}\text { Good planning results in the "optimal" positioning of } \\
\text { resources. Are the resources staged for efficient work? }\end{array}$ \\
\hline & Work tool fitness & $\begin{array}{l}\text { Each job requires a set of tools that fit the task at hand. } \\
\text { Are machines and labourers equipped with suitable } \\
\text { tools? }\end{array}$ \\
\hline & Motion efficiency & $\begin{array}{l}\text { Mobile system need appropriate space to move safely } \\
\text { and efficiently (e.g., a loader and truck combination). } \\
\text { Are the motions of the systems efficient? }\end{array}$ \\
\hline \multirow{3}{*}{ Effort and Skill } & $\begin{array}{l}\text { Reflective thinking- } \\
\text { quality control }\end{array}$ & $\begin{array}{l}\text { Is the sketch drawn with care? (e.g., sharp lines) Does } \\
\text { the sketch fit the paper? Are the laws of physics } \\
\text { adhered to? }\end{array}$ \\
\hline & Neatness & $\begin{array}{l}\text { Is the final product clean and presentable to a future } \\
\text { employer? }\end{array}$ \\
\hline & Artistic sophistication & Does the author show some artistic sophistication? \\
\hline
\end{tabular}

Sepasgozar, S. and Bernold, L. (2012) 'Engineering sketching: a valuable tool in construction', Australasian Journal of Construction Economics and Building, Conference Series, 12 (1) 62-72 
The following sections explain how this ESTL was implemented and tested for the course mentioned earlier.

\section{Implementation of Model}

CVEN2101, Engineering Construction, builds on and expands the understanding of math, physics and materials. The course's objectives include: (1) introduction key construction technologies, (2) the modelling process and methods (3) productivity assessment and (4) construction safety. Engineering sketches were heavily used in presenting the class material in the textbook and the lecture using MS Powerpoint. In order to help the student to develop sketching skills for engineering a special workshop was held, and frequently students were encouraged to visit visual on-line sources related to the topic. URL addresses were given in the Powerpoint. In addition, the wonderful engineering sketches by Leonardo da Vinci and Agricola were studied and their methods of using light and shade to provide depth and texture were admired.

The first sketching assignment required a 3-view orthogonal sketch of a large offhighway hauling truck. The students were guided by tutors during one tutorial. A list of criteria was provided to help students self-assess the quality of their work. Examples of the criteria include: 1) Proper scaling of the truck chassis as a function of tire size, b) treads of tires and connections to truck axle, c) safety railing for driver, and d) four tires in back and only two in front. Students were taught about shading to create depth and texture. The first submissions were immediately critiqued by the trained tutors. Ninety-nine percent of the sketches did not meet expectations and were returned immediately to the students for improvement. Following the principle of formative assessment no mark was given until the students submitted a passing sketch. The following sketches increased in complexity.

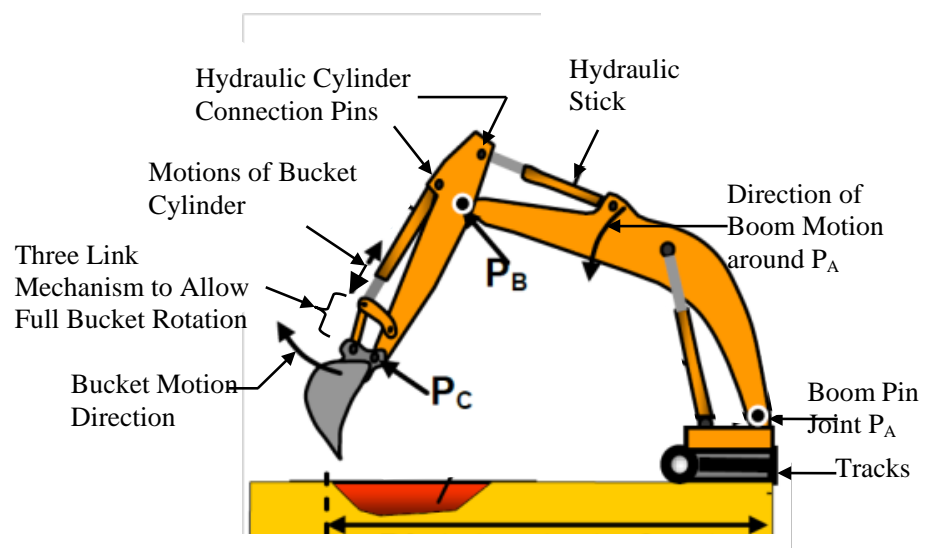

Figure 2 Sample engineering sketch of backhoe excavator arm in textbook

\section{Textbook Sketches Used to Provide Examples}

Engineering sketches are simple drawings of a system that show the main functional elements within a proper work environment and in a stable safe situation. Figure 2 displays an example from chapter 4 in the textbook where backhoe excavators are discussed. It illustrates the

Sepasgozar, S. and Bernold, L. (2012) 'Engineering sketching: a valuable tool in construction', Australasian Journal of Construction Economics and Building, Conference Series, 12 (1) 62-72 
system equipment containing the functional components, indicates the motions needed to execute the main tasks, the actuators providing the necessary forces, and the geometrically correct pin joints (PA-PC), within an appropriate work environment. Furthermore, the excavator bucket, boom, stick, cylinders and connections are scaled appropriately while colours are used to differentiate between various materials (eg. grey for the high strength steel for the hydraulic piston rod, and reddish clay, white lined pin joint connections).

\section{Sample Assessments using ESTL}

A few presented sketches were selected in order to demonstrate the use of the ESTL. The reader will notice that the quality in terms of engineering accuracy deteriorates, reflecting the increased complexity and understanding required to complete the sketches. The results of some of the assigned sketches are discussed in the following section:

\section{First Theme: Off-highway Truck}

Three photographs of an off-highway truck (see Figure 3) established the basis for the first assignment during the week when construction trucks were covered in class. The goal was to create an orthogonal representation of the truck (front, sides and top) that showed all the main components in proper scale and expressing their purpose and function. Of course, the object had to be drawn from a perfectly perpendicular observation angle requiring the students to adjust its spatial orientation. The three examples shown in Figure 3 are representative of the differences in quality of the third group of submissions (the student had to pass a minimum requirement). These sketches met basic criteria such as the dump box, approximately round wheels, safe stairs for driver, enclosed cabin, and rock-fall roof protection. Figure $3 \mathrm{~b}$ ) presents the work of an "artistically" inclined sketcher who is using light and shade to define the shape and tread of the tires and the undercarriage, while emphasizing the steel ribs supporting the bottom of the dump box. Similar to Leonardo's technique, the bright ribs receive artificial lighting as they are in fact located in the dark (see Figure 3 a).

It is apparent that sketch (d) takes a lot of "liberty" depicting the actual object starting with off-centered and odd-shaped back tires. The cabin underneath the "high" roof as well as the stairs in the front looks mysterious. Finally, the wheels lack the important bolts connecting them to the suspension system. 


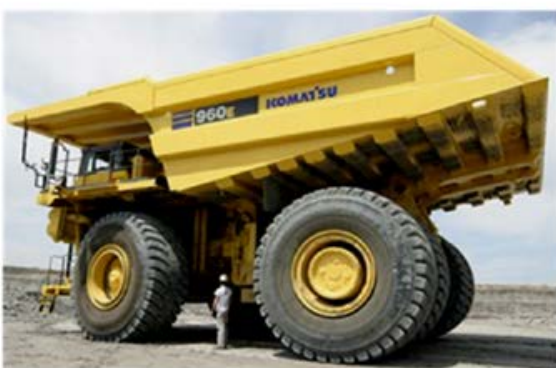

b) Photograph of slightly turned off-highway truck

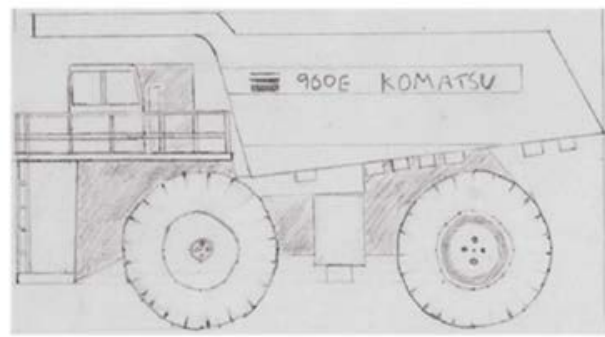

c) "No-frills" side view of hauling truck with simple shading

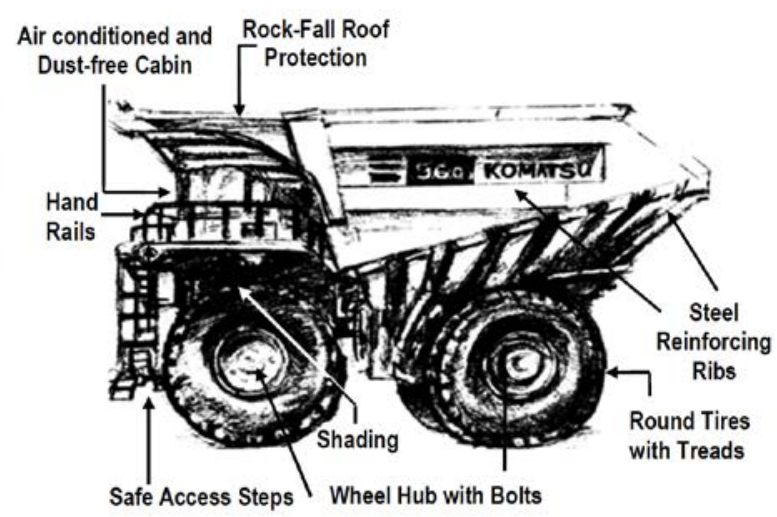

a) "Artistic" side view sketch given the highest evaluation

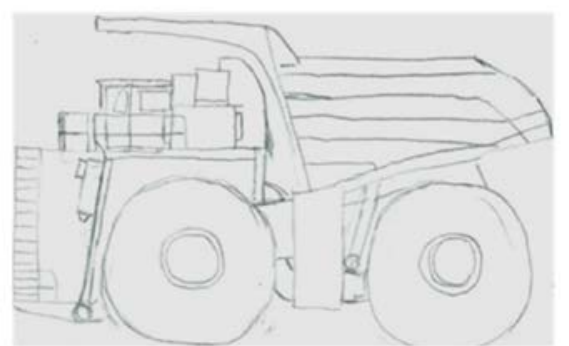

d) Out-of-scale "rough" and minimal side view sketch

Figure 3. Sample side-view sketches of large off-highway truck (labeling by authors)

\section{Second Theme: Telling the Story about the Backhoe Accident}

As noted above, the second sketching assignment was rather more complex. In fact, it was tailored after Agricola's depiction of pumping water out of deep mines in the Middle-Ages. He does not simply draw the pump technology but depicts the entire system in action inside the mine with people working, an operator activating the pump and the owner talking with the engineer on the surface.

The students were given a short paragraph describing an accident where a backhoe digging a trench pulled, but did not break, a buried gas pipe thus disconnecting it from the gas meter box close to a house. The escaping gas percolated through the soil and into the basement of the house where it suddenly exploded, destroying the house. The objective was to tell the story of the accident on one sheet of paper so that an engineer would know in 5 seconds what happened. 


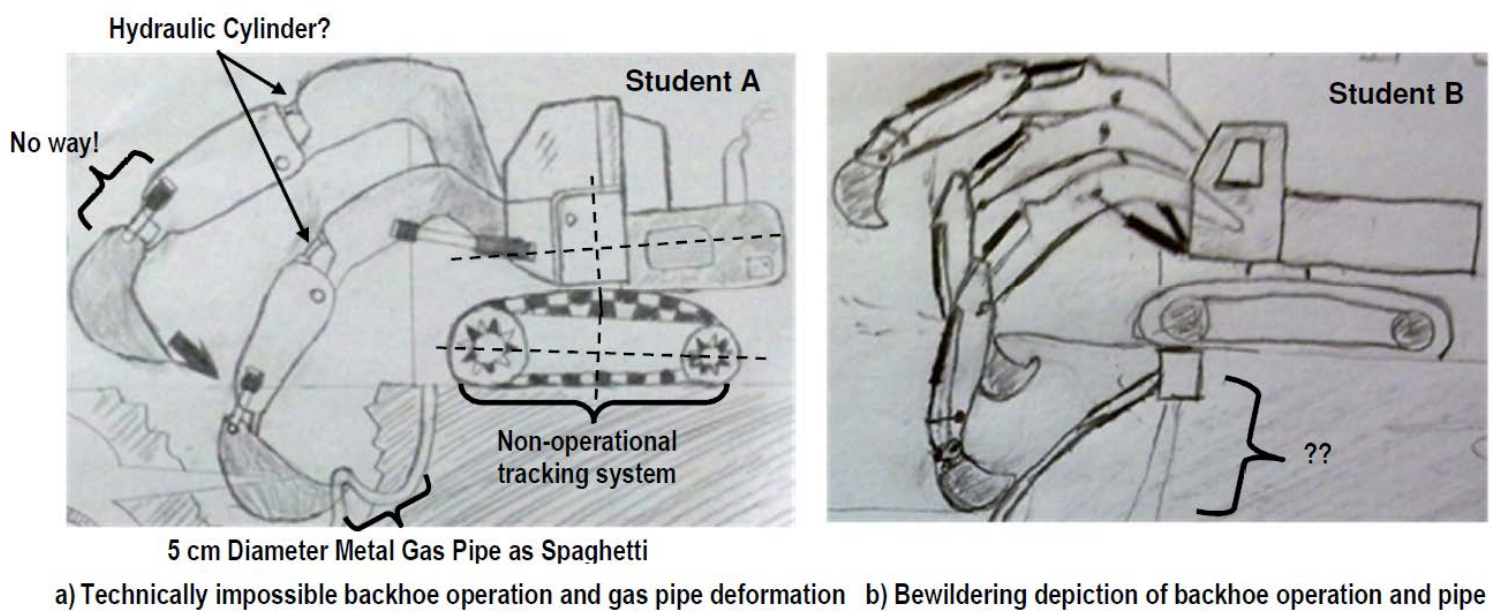

Figure 4 Comparison of digging operation and gas pipe pulling

The two samples, only key sections from the submitted sketch, need to be evaluated knowing that chapter 4 in the textbook as well as the Powerpoint of the week depicted numerous backhoe excavators in sketch format and in photographs. One such example was presented above in Figure 2. While Student B was able to draw the main components of the machine relatively accurately Figure 4 a) indicates a lack of mechanical as well as operational understanding. Several key mechanisms clearly drawn and labeled in Figure 2 are turned into impossible objects. The gas pipe has turned into spaghetti and the rotating upper body rests on an axle that must be broken. Student B has similar problems in that the "How did it Happen?” question is left to one's imagination.

In summary, the two examples lacked elements in all four outcome areas:-

Competency A: Student A presents two mechanical systems that are non-functional while Student B lacks understanding of how the mechanical and pipe systems interact.

Competency B: While Student B seems to comprehend the application of power to operate, Student B totally deficient in competence area B.

Competencies C and D: Not applicable.

Competency E: Both students also lack in reflective thinking about the physical constraints of the operation. Neatness and artistic sophistication are also lacking.

\section{Third Theme: Lift Plan for Mobile Cranes}

This last theme extended the task of presenting "What Happened and Why?" to presenting a plan for the safe execution of a critical operation. Following the topics of the course, sketch 3 was dedicated to learning about cranes. The root of the assignment was another accident where two truck cranes were to dismantle an old observation tower but collapsed one after the other. During class, the safe operation of cranes was extensively discussed, supported with sample calculations, quizzes and lift capacity tables from actual crane operations. Photographs of the accident were shown in Powerpoint. Most importantly, the textbook contained additional sketches depicting the events supplemented with a step-by-step discussion of what happened. Figure 5 displays a figure from the textbook presenting a sideview of the lifting arrangement (crane 1 is hidden). The plan was to lift the entire tower structure at the far side, close to the power lines, causing the tower to tilt forward thus

Sepasgozar, S. and Bernold, L. (2012) 'Engineering sketching: a valuable tool in construction', Australasian Journal of Construction Economics and Building, Conference Series, 12 (1) 62-72 
starting a rotating motion with the footing of the front legs as the center. It did not turn out as planned.

The textbook as well as the class presentation highlighted two common causes of fatal accidents: a) Lack of critical reinforcement, and b) eccentric lifting at the beginning of the lift. Figure 5 highlights that both requirements were violated as the tower base leg, suddenly experiencing side loading, was not reinforced and the hitch line, an extension of the load line, was inclined because of the extended roof. The students were shown how the two cranes collapsed starting with the buckling of one of the front tower legs adding abruptly to the sideloading of the boom belonging to crane 1 .

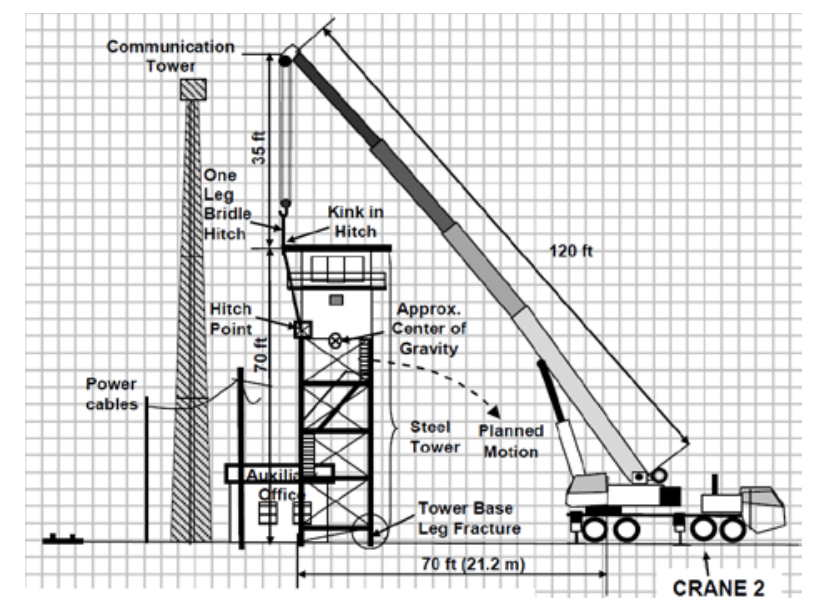

Figure 5 Sketch of situation prior to lifting

This assignment asked the students to design a plan that would ensure a safe dismantling of the observation tower. In support of the assignment, the students were presented with the rules and regulations as well as with successful examples of similar work. Figure 6 presents two common submissions.

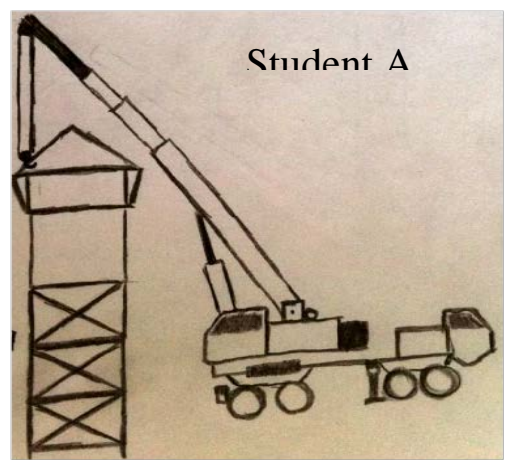

a) Unsafe Operation and Crane Set-up

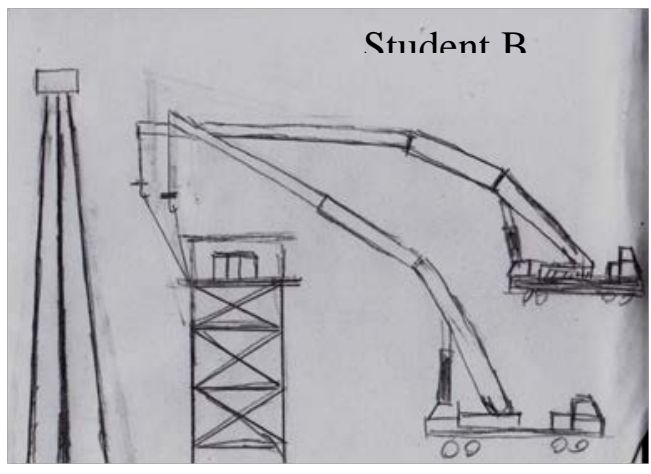

b) Dangerous Lift Plan Disregarding Basic Rules

Figure 6 Lift plant depicting the understanding of forces and mechanical behaviour

Using the ESTL matrix one is able to quickly assess the quality of the two sketches:-

Competency A: Especially Student B lacks an understanding of how truck cranes have to be deployed or operate their telescoping booms. The crane drawn by Student A lacks plumbness and stability through appropriate outriggers. Student B, on the other hand, lacks any kind of

Sepasgozar, S. and Bernold, L. (2012) 'Engineering sketching: a valuable tool in construction', Australasian Journal of Construction Economics and Building, Conference Series, 12 (1) 62-72 
comprehension of truck cranes. In particular, none of the telescoping crane booms could be deployed correctly.

Competency B: Student A shows a tower without sufficient stability, lack of hitching details, and a crane without outriggers. Student B draws a non-vertical hitching arrangement that was repeatedly discussed as being unacceptably dangerous. In addition, the trucks rest on their tires, a clear violation of basic requirements that were mentioned repeatedly in class.

Competency C: Workplace safety was ignored by both students.

Competency D: Both students lacked any preparatory steps, plan of action or emergency procedures in the event that problems occurred.

Competency E: It is apparent that neither reflective thinking has taken place, nor were the cranes drawn neatly, nor with any artistic sophistication.

\section{Summary and Conclusion}

Sketches have a long history as effective means of representing complex systems that could take 1,000 words to describe. Leonardo da Vinci and Agricola are just two "giants" of engineering that embraced this tool to communicate, explain and "narrate" the behaviour of complex systems. This paper argued that sketching could also be a powerful tool to boost teaching and learning of subjects in engineering. The unique capacity of sketching allows students to demonstrate how to apply learned principles to "virtual" but nevertheless pertinent real-world situations. The presented model based on assessment criteria helps to reveal the level of understand by the way the student portrays key elements in the engineering sketch. The heart of the proposed concept is the non-verbal and non-mathematical approach to demonstrate deep understanding. The paper also revealed how sketches assist students to deeply understand construction systems and equipment in static and dynamic conditions.

Comprehension on the part of the students has to be exhibited by logically and safely relating tasks, structural elements, actuators and the motions necessary to produce desired outcomes. In addition, sketching can be readily leveraged by formative assessment where students learn how to review and improve their own work. The models need to express how forces are applied to create desired motions and how stability is guaranteed. Finally, an understanding of the steps required to guarantee the safety and health of everybody has to result in the necessary safety provisions. The ESTL model is offered as a framework to link learning outcomes to desired competencies, outcome attributes and measures of understanding. Future work is dedicated to generalize the present model in order to make it applicable to other courses in engineering. The use of the matrix was explained using three sketching assignments for the course Engineering Construction, a second year course at UNSW.

\section{References}

Barr, R.E. (2004) 'The current status of graphical communication in engineering education.' Frontiers in Education, 2004. FIE 2004. 34th Annual.

Company, P., Piquer, A., Contero, M. and Naya, F. (2005). 'A survey on geometrical reconstruction as a core technology to sketch-based modeling.' Computers \&amp; Graphics, 29, 892-904.

Sepasgozar, S. and Bernold, L. (2012) 'Engineering sketching: a valuable tool in construction', Australasian Journal of Construction Economics and Building, Conference Series, 12 (1) 62-72 
Garner, S.W. (1990). 'Drawing and designing: the case for reappraisal.' Journal of Art \& Design Education, 9, 39-55.

Henderson, K. (1991). 'Flexible sketches and inflexible data bases: visual communication, conscription devices, and boundary objects in design engineering.' Science, Technology \& Human Values, 16, 448-473.

Prats, M., Lim, S., Jowers, I., Garner, S.W. and Chase, S. (2009). 'Transforming shape in design: observations from studies of sketching'. Design Studies, 30, 503-520.

Reynolds, S., Johnson, J., Piburn M., Leedy, D., Coyan J., Busch, M. and Gilbert, J. (2005). Visualization in undergraduate geology courses, Visualization in Science Education, Springer, Netherlands.

Tversky, B. (2002). 'What do sketches day about thinking?' Proc., AAAI Spring Symposium on Sketch Understanding.

Varley, P. and Company, P. (2008). 'Automated sketching and engineering culture', VL/HCC Workshop. Germany.

Verstijnen, I.M., Van Leeuwen, C., Goldschmidt, G., Hamel, R. and Hennessey, J. M. (1998). 'Sketching and creative discovery.' Design Studies, 19, 519-546.

White, M. (2000). Leonardo the First Scientist. Little, Brown and Company, London. 